\title{
COMPARATIVE STUDY OF SLOT LOADED RECTANGULAR AND TRIANGULAR MICROSTRIP ARRAY ANTENNAS
}

\author{
G M Pushpanjali ${ }^{1}$, R B Konda ${ }^{2}$, S K Sajjan ${ }^{3}$ \\ ${ }^{1}$ Asst. Prof., Dept. of Physics, Central University of Karnataka, Gulbarga \\ ${ }^{2}$ Asst. Prof., Dept. of Electronics, Smt. V. G. Degree College for Women, Gulbarga 585102 \\ ${ }^{3}$ Asso. Prof., Dept. of Electronics, S.V.M, Arts, Sc. and Comm. College, Ilkal (Karnataka) 587125
}

\begin{abstract}
In this paper we have presented the comparative study and theoretical validation of two element slot loaded rectangular microstrip array antenna (TS-RMAA) and two element slot loaded equilateral triangular microstrip array antenna (TS-ETMAA), fed by corporate feed technique illustrating wide band operation. The experimental results reveal that, the impedance bandwidth of TSRMAA is $6.54 \%$ (i.e., $700 \mathrm{MHz}$ ) and the impedance bandwidth of TS-ETMAA is $7.35 \%$ (i.e., $820 \mathrm{MHz}$ ). The impedance bandwidth of TS-ETMAA is 1.12 times more than the impedance bandwidth of TS-RMAA. The theoretical impedance bandwidth is determined to compare the experimental impedance bandwidth for validation. The theoretical and experimental impedance bandwidth is in close agreement with each other. The wide band operation of the antenna may find application in communication system.
\end{abstract}

Keywords: Array antenna, wide band microstrip antenna, triangular microstrip antenna.

\section{INTRODUCTION}

With the saturation of low frequency bands, the operating frequencies of modern communication systems have risen and planar antennas have become more attractive. Among them, microstrip antennas form a special category on which considerable research work has been conducted. However microstrip antennas inherently have a narrow impedance bandwidth and its enhancement is usually demanded for practical applications. On the other hand, wide band antenna with small physical size and good performance are an oncoming challenge to meet the needs of integration, cost and efficiency of the emerging wireless world.

One of the most attractive features of the equilateral triangular microstrip antenna (ETMSA) is that, the area necessary for the patch becomes about half as large as that of a nearly rectangular or square microstrip antenna designed for the same frequency [1]. In view of this an effort is made to enhance the impedance bandwidth of the antenna by reducing the area of the radiating patch.

\section{DESCRIPTION OF THE ANTENNA GEOMETRY}

The antennas are sketched by using computer software AutoCAD and fabricated on low cost glass epoxy substrate material of thickness $h=1.66 \mathrm{~mm}$ and permittivity $\varepsilon_{\mathrm{r}}=4.2$. The radiating elements of TS-RMAA and TS-ETMAA shown respectively in Fig.1 and Fig.2 are fed by using corporate feed technique.
- ***

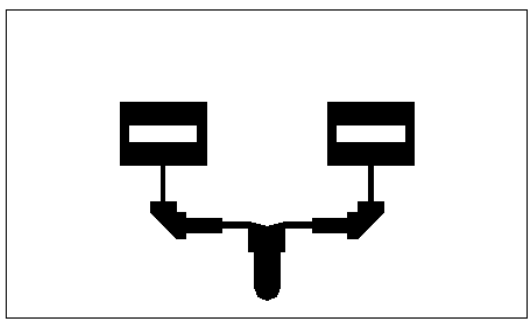

Fig - 1: Designed geometry of TS-RMA

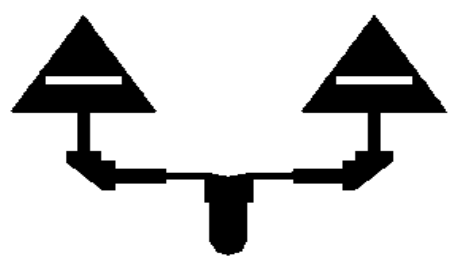

Fig - 2: Designed geometry of TS-ETMAA

This technique has been selected because of its simplicity and it can be simultaneously fabricated along with the antenna elements. In Fig. 1 and Fig. 2 the distance between the two radiating elements $D_{R}$ is kept at $3 \lambda_{0} / 4$ in order to add the radiated power in free space by individual elements to improve antenna parameters. However, the $D_{R}$ is taken in terms of multiple of half wavelength. But in this case $3 \lambda_{\mathrm{o}} / 4$ has been selected in order to accommodate corporate feed arrangements between the two radiating elements. The corporate feed arrangement consists of matching transformer, quarter wave transformer, microstrip bend and two way power 
divider used for better impedance matching between feed and radiating element which reduces the loss in the feed line At the tip of microstrip line feed [2] a $50 \Omega$ coaxial SMA co-axial connector is used for feeding the microwave power.

\section{EXPERIMENTAL RESULTS}

The impedance bandwidth over return loss less than $-10 \mathrm{~dB}$ for the proposed antennas is measured for X-band frequencies. The measurement is taken on Vector Network Analyzer (Rohde \& Schwarz, Germany make ZVK model).

The variation of return loss versus frequency of TS-RMAA and TS-ETMAA is shown in Fig. 3 and 4 respectively. From these graphs the impedance bandwidth is determined by using the equation:

$$
\mathrm{BW}=\left[\frac{\left(f_{2}-f_{1}\right)}{f_{c}}\right] \times 100 \%
$$

Where, $f_{1}$ and $f_{2}$ are the lower and upper cut off frequency of the band respectively, when its return loss becomes $-10 \mathrm{~dB}$, and $f_{c}$ is a centre frequency between $f_{1}$ and $f_{2}$. The experimental result shows the impedance bandwidth of TSRMAA is $6.54 \%$ and the impedance bandwidth of TSETMAA is $7.35 \%$.

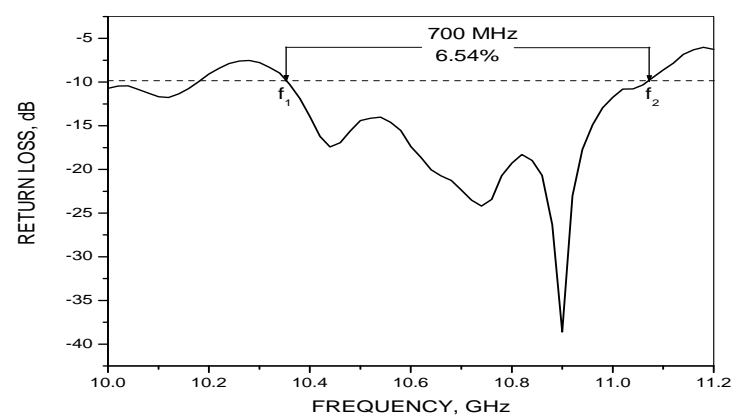

Fig - 3: Variation of return loss versus frequency of TSRMAA

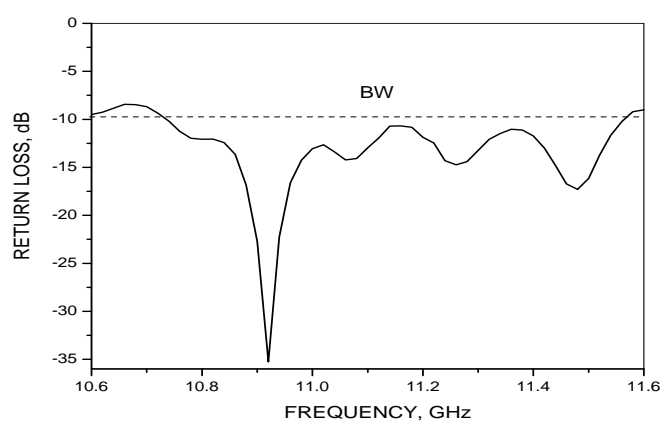

Fig - 4: Variation of return loss versus frequency of TSETMAA

\section{THEORETICAL RESULTS}

The proposed antennas TS-RMAA and TS-ETMAA have been designed for $\mathrm{TE}_{10}$ mode.

The expression derived by Girish Kumar and K. P. Ray [3] for the calculation of percentage impedance bandwidth are in terms of patch dimensions and substrate parameters for conventional rectangular microstrip antenna and is given by,

$$
\text { Impedance Bandwidth }(\%)=\left[\frac{\mathrm{A} \times \mathrm{h}}{\lambda_{0} \sqrt{\varepsilon_{\mathrm{r}}}}\right] \times \sqrt{\frac{\mathrm{W}}{\mathrm{L}}}
$$

Where

$\mathrm{h}=$ thickness of the substrate

$\varepsilon_{\mathrm{r}}=$ relative permittivity of the substrate

$\mathrm{W}=$ width of the patch

$\mathrm{L}=$ length of the patch

$\lambda_{0}=$ free-space wavelength

$\mathrm{A}=$ correction factor

The correction factor ' $A$ ' changes as the value of factor $\left[\frac{\mathrm{h}}{\lambda_{0} \sqrt{\varepsilon_{\mathrm{r}}}}\right]$ changes [4], which is given by;

$A=180$ for

$$
\left[\frac{\mathrm{h}}{\lambda_{0} \sqrt{\varepsilon_{\mathrm{r}}}}\right] \leq 0.045
$$

$A=200$ for

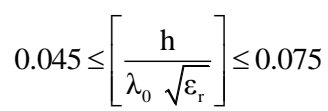

$A=220$ for

$$
\left[\frac{\mathrm{h}}{\lambda_{0} \sqrt{\varepsilon_{\mathrm{r}}}}\right] \geq 0.075
$$

In the present investigation the value of correction factor $\mathrm{A}$ is taken as 180 because the calculated value of $\left[\frac{\mathrm{h}}{\lambda_{0} \sqrt{\varepsilon_{\mathrm{r}}}}\right] \mathrm{TS}$ RMAA and TS-ETMAA is lesser than 0.045 determined for the known value of $h, \lambda_{0}$ and $\varepsilon_{\mathrm{r}}$.

Since the expression (1) given by [3] is for single element RMSA. This equation is extended for calculating the impedance bandwidth of RMAAs by multiplying the ratio $\frac{W}{L}$ by $\mathrm{n}$. The extended equation becomes,

$$
\text { Impedance Bandwidth }(\%)=\left[\frac{\mathrm{A} \times \mathrm{h}}{\lambda_{0} \sqrt{\varepsilon_{\mathrm{r}}}}\right] \times \sqrt{\mathrm{n} \times \frac{\mathrm{W}}{\mathrm{L}}}
$$


Where, $\mathrm{n}=$ number of rectangular radiating patches in RMAAs.

If the radiating elements are equilateral triangular in shape The equation (1) is converted for equilateral triangular microstrip antenna and arrays by replacing the W/L ratio with $\left(n \times S_{e}\right)$. The modified equation for ETMA is given by

$$
\operatorname{Impedance} \operatorname{Bandwidth}(\%)=\left[\frac{\mathrm{A} \times \mathrm{h}}{\lambda_{0} \sqrt{\varepsilon_{\mathrm{r}}}}\right] \times \sqrt{\mathrm{n} \times \mathrm{S}_{\mathrm{e}}}
$$

Where, $S_{e}=$ effective side length of the equilateral triangular radiating patch and

$\mathrm{n}=$ number of radiating patches.

In equation (3) the value of $S_{e}$ is given by the formula [4]

$$
\mathrm{S}_{\mathrm{e}}=\mathrm{S}+\frac{4 \mathrm{~h}}{\sqrt{\varepsilon_{\mathrm{e}}}}
$$

Where

$\mathrm{S}=$ side length of the equilateral triangular microstrip patch

$\varepsilon_{e}=$ effective dielectric constant

In TS-RMAA and TS-ETMAA the rectangular slots are loaded at the center of the radiating elements The insertion of slot changes the impedance of conducting patch. Therefore for determining the impedance bandwidth of area of slot loaded rectangular and triangular microstrip radiating patches $\left(\mathrm{A}_{\mathrm{SP}}\right)$ and capacitance of the slot $\left(\mathrm{C}_{S}\right)$ are taken into consideration. The $\mathrm{C}_{\mathrm{S}}$ is calculated with the help of the transmission line model [2]. This analytical technique is based on equivalent magnetic current distribution around the patch edges which is similar to slot antennas.

The change of impedance of patch mainly depends upon the area of slot and its location as the impedance of the patch is non-linear [3]. The effective resonance characteristics due to change of impedance is given by multiplying the ratio W/L by $A_{S P}$ in equation 2 and by $S_{e}$ in equation 3. Since slots are on the radiating patches separated by the ground plane by substrate of thickness $\mathrm{h}$ The slot behaves as capacitor and resonates as secondary resonator to the main patch. The resonance of slot if close to the main patch which causes enhancement in the impedance bandwidth The capacitive associated to the slot is $\mathrm{C}_{\mathrm{S}}$. The term $\mathrm{C}_{\mathrm{S}}$ is added to equation 2 and 3 to determine total resonance of TS-RMAA and TSETMAA. The capacitance parameter $\mathrm{C}_{\mathrm{S}}$ associated to the slot is evaluated using the transmission line model [2] given by;

$$
\mathrm{C}_{\mathrm{S}}=\frac{\Delta \mathrm{l} \sqrt{\varepsilon_{\mathrm{eff}}}}{\mathrm{c} \times \mathrm{Z}_{0}}
$$

Where, $\Delta \mathrm{l}$ is the extension length and $\varepsilon_{\text {eff }}$ is the effective dielectric constant. Hence equation (2) for TS-RMAA becomes,

$$
\text { Impedance Bandwidth }(\%)=\left\{\frac{\mathrm{A} \times \mathrm{h}}{\lambda_{0} \sqrt{\varepsilon_{\mathrm{r}}}} \times \sqrt{\mathrm{n} \times \frac{\mathrm{W}}{\mathrm{L}} \times \mathrm{A}_{\mathrm{SP}}}\right\}+\mathrm{C}_{\mathrm{S}}
$$

And for TS-ETMAA is,

Impedance Bandwidth $(\%)=\left[\left(\frac{\mathrm{A} \times \mathrm{h}}{\lambda_{0} \sqrt{\varepsilon_{\mathrm{r}}}}\right) \times \sqrt{2 \times \mathrm{S}_{\mathrm{e}} \times \mathrm{A}_{\mathrm{sp}}}\right]+\mathrm{C}_{\mathrm{s}}$

Where

$\mathrm{n}=2$ as proposed antennas consists of two radiating elements.

$\mathrm{A}_{\mathrm{SP}}=$ area of the slot loaded patch excluding the area of rectangular slot

$\mathrm{C}_{\mathrm{S}}=$ capacitance of the slot

The value of $A_{s p}$ in equation (6 and 7) is calculated by using the formula

$$
\mathrm{A}_{\mathrm{SP}}=\mathrm{A}_{\mathrm{P}}-\mathrm{A}_{\mathrm{S}}
$$

Where

$\mathrm{A}_{\mathrm{p}}=$ area of patches.

$\mathrm{A}_{\mathrm{s}}=$ area of rectangular slots

The value of $A_{P}$ is for the given antennas are determined using basic formulae for rectangular and equilateral triangular geometries. In the above equation $8, \mathrm{~A}_{\mathrm{S}}$ is obtained by the formula;

$$
\mathrm{A}_{\mathrm{S}}=\mathrm{L}_{\mathrm{S}} \times \mathrm{W}_{\mathrm{S}}
$$

Where

$\mathrm{L}_{\mathrm{S}}=$ length of the rectangular slot

$\mathrm{W}_{\mathrm{S}}=$ width of the rectangular slot

The impedance bandwidth of TS-RMAA and TS-ETMAA is calculated using the equation (6) and (7) is recorded in Table 1.

\section{CONCLUSIONS}

From the detailed experimental study it is found that, the proposed antenna TS-ETMAA is quite capable of enhancing the impedance bandwidth by $12.38 \%$ and compactness of $10.71 \%$ when compared to TS-RMAA. This shows the superiority of ETMSA in enhancing the impedance bandwidth. Experimental impedance bandwidth is verified theoretically. The theoretical and experimental impedance bandwidth is in close agreement with each other. These 
antennas are simple in their geometries and the feed line can be fabricated along with the radiating patches. Such antennas may find applications in the microwave communication systems.

Table -1: Various antenna parameters

\begin{tabular}{|c|c|c|c|c|c|c|c|}
\hline \multirow{2}{*}{ Antennas } & \multicolumn{4}{|c|}{ Parameters } & \multicolumn{2}{c|}{ Impedance bandwidth (\%) } \\
\cline { 2 - 8 } & $\begin{array}{c}\text { Minimum return } \\
\text { loss in dB }\end{array}$ & VSWR & $\begin{array}{c}\text { HPBW in } \\
\text { dB }\end{array}$ & $\begin{array}{c}\text { Gain } \\
\text { in dB }\end{array}$ & $\begin{array}{c}\text { Nature of } \\
\text { impedance } \\
\text { bandwidth }\end{array}$ & Theoretical & Experimental \\
\hline TS-RMAA & -38.61 & 1.02 & 43.91 & 4.7 & Single band & 5.55 & 6.54 \\
\hline TS-ETMAA & -35.26 & 1.04 & 42.34 & 4.14 & Single band & 7.12 & 7.35 \\
\hline
\end{tabular}

\section{REFERENCES}

[1] Pushpanjali G.M., Konda R.B., Mulgi S.N., Satnoor S.K., and Hunagund P.V., "Equilateral triangular microstrip array antenna for broadband operation", International Journal of Microwave and Optical Technology Letters, Vol. 50, pp. 1834-1837, July 2008.

[2] Bhal I J and Bhartia P, Microstrip Slot Antennas, Microstrip Antennas, Dedham, MA: Artech House, pp. 221-245, 1981.

[3] Girish Kumar and K. P. Ray, Broadband Microstrip Antennas, Norwood, MA: Artech House, 2003.

[4] Constantine A Balanis, Arrays: Linear, Planar, and Circular, Antenna Theory Analysis and Design, John Wiley \& Sons Inc., New York, pp. 204-282, 1982.

\section{BIOGRAPHIES}

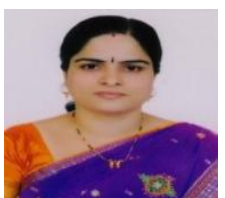

Dr. G. M. Pushpanjali, is presently working as an Assistant Professor at Department of Physics, Central University of Karnataka, Gulbarga, India. She is an active researcher in the area of microwave communication and applied electronics with the teaching and research experience of more than 10 years. In recognition she is awarded with best research paper award for her work in antenna design. Along with academics she holds national recognition for social service and welfare.

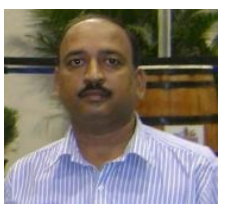

Dr. R B Konda received his M.Sc and Ph.D degree from Gulbarga University, Gulbarga in the field of Electronics in the year 1992 and 2009 respectively. $\mathrm{He}$ is working as Asst. Professor in Electronics in Smt V. G. Degree College for Women, Gulbarga since 1992. He is an active researcher in the field of Microwave Electronics.

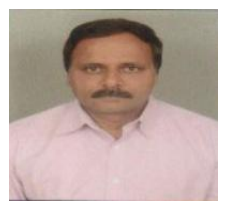

Sri. S. K.Sajjan, received his M.Sc degree from Gulbarga University, Gulbarga in Electronics in the year 1991. He is working as Associate Professor in the Dept. of Electronics, S.V.M, Arts, Sc. and Comm.
College, Ilkal since 1991. He is an active researcher in the field of Microwave Electronics. 